\title{
O Quarto Elemento...
}

Amilcar Zani

Universidade de São Paulo amilcarzani@gmail.com

Heloisa Zani

Universidade de São Paulo

heloisazani@gmail.com

Resumo: Apresentar um panorama da vida de Edward Steuermann é ação imprescindível para se conhecer, entender, recuperar e reconhecer a dimensão da importância e do sentido que sua atuação como pianista, professor e compositor conferiu à Segunda Escola de Viena e à história da musica do Século XX e seus desdobramentos. Este texto expõe, de maneira concisa, a trajetória de Steuermann como pianista, seu encontro com Schoenberg, seu envolvimento com a "musica moderna" como performer e compositor, e o crescimento e a afirmação de suas atividades como professor. Apesar de ainda pouco conhecido do publico e do meio acadêmico, sua história se caracteriza pela competência, lucidez e determinação. Sua postura sempre foi discreta e não sensacionalista, e talvez por esta razão tenha permanecido injustamente negligenciado.

Palavras-chave: Memórias, Segunda Escola de Viena, Piano, Ensino, Composição.

\section{The Fourth Element...}

Abstract: Presenting an overview of Edward Steuermann's life is an essential action to know, understand, recover and recognize the dimension of the importance and meaning that his activities as a pianist, teacher and composer gave to the Second Viennese School and to the history of 20th century music and its effects. This work presents, in a concise way, Steuermann's trajectory as a pianist, his encounter with Schoenberg, his involvement with "modern music" as a performer and composer, the growth and affirmation of his teaching activities. Although still not well known by the public and the academic world, his life and work are marked by competence, lucidity and determination. His posture has always been discreet and not sensational, and perhaps for this reason it has remained unfairly neglected.

Keywords: Memories, Second Viennese School, Piano, Teaching, Composition.

\section{Introdução}

Qualquer pessoa que se aproxime da Segunda Escola de Viena se depara com a dimensão que esta corrente estética teve, não apenas na mudança dos padrões e da linguagem musical no final do Séc. XIX e início do Séc. XX, mas também sua influência em toda a produção musical do Ocidente a partir da proposta transformadora de Arnold Schoenberg e de seus discípulos Alban Berg e Anton Webern. Se o papel da Segunda Escola de Viena foi determinante em relação ao movimento musical contemporâneo, para esta foi igualmente determinante a figura de Edward Steuermann. Com sua qualidade enquanto pianista e seus estudos formais de composição com Schoenberg, ele parecia predestinado ao papel de principal interprete da escola de Schoenberg. (ADORNO, 1982, p. 311). A partir de sua atuação como ensaiador e pianista 
da primeira audição do Pierrot Lunaire op.21 em 1912, não apenas apresentou em primeiras audições a obra para piano de Schoenberg, Webern e Berg, mas tornou-se parte essencial e insubstituível do desenvolvimento da música no Século XX.

A Coleção Clara e Edward Steuermann, na Divisão de Musica da Biblioteca do Congresso de Washington, nos Estados Unidos, abriga a documentação relativa à vida e ao trabalho de Edward Steuermann. Contém escritos, partituras manuscritas e editadas, a correspondência de Clara e Edward Steuermann e o conjunto da correspondência familiar e geral em um período que abrange cerca de sessenta anos, principalmente entre as décadas de 1930 e 1970. (STEUERMANN, 1982). A consulta e pesquisa deste material torna possível reconstruir a trajetória de Steuermann. Correspondências pessoais contém mais do que uma mera sequência de fatos e posicionamentos, e revelam um universo de informações. Este artigo apresenta uma visão geral do macrocosmo de realizações, ensinamentos, ideias, ideais e, também, de desventuras, que constituem o percurso da vida de Edward Steuermann. (ZANI, 2002, p. 15).

\section{Início}

Edward Steuermann nasceu em 18 de junho de 1892, em Sambor, cidade no sul da Polônia ${ }^{1}$. Seu pai, Josef Steuermann, era advogado e durante dezoito anos foi prefeito da cidade, sendo respeitado pelo governo austríaco por sua habilidade política. (VIERTEL, 1969, p.7). Figura importante no desenvolvimento de sua cidade, não possuía identidade religiosa com a comunidade judaica, embora fosse judeu. Sua casa era um ponto de encontro de personalidades que vinham de Lemberg, principal cidade da Galícia. Colocava-se, social e politicamente, como cidadão polonês (Idem).

Augusta Amster, sua mãe, de ascendência austro-germânica, nasceu na Rússia e possuía uma formação musical considerável. Havia estudado piano e canto, inclusive em Viena, pois pretendia tornar-se cantora lírica. Problemas financeiros familiares obrigaram-na a abandonar seus planos e viver em Czernowitz, na Romênia, onde conheceu e casou-se com Josef

\footnotetext{
${ }^{1}$ Sambor situa-se na Galícia, região da Europa centro-oriental, cujo território está dividido atualmente entre a Polônia e a Ucrânia. À época do nascimento de Edward Steuermann, pertencia à coroa do Império AustroHúngaro. Desde o Século XIV até o início da Segunda Guerra Mundial permaneceu alternadamente sob os domínios Polonês e Austríaco.
} 
Steuermann, mudando-se com ele para Sambor ${ }^{2}$. (STEUERMANN, 1922, Caixa 2). Sua formação como cantora iria influenciar, profissionalmente, três de seus filhos: $\mathrm{Salka}^{3}$, Rosa e Edward. Um quarto filho, Zygmunt, sete anos mais novo que Edward, foi o único a não seguir uma atividade artística, tornando-se conhecido como jogador de futebol ${ }^{4}$.

Edward foi encaminhado para a música desde a infância. Sua mãe se incumbiu de sua educação musical, ao mesmo tempo que tutores se encarregavam de sua formação escolar em casa, como era costume da alta burguesia na época. Apenas os exames eram realizados no Ginásio em Sambor, os quais incluíam Latim, Grego e Alemão como disciplinas obrigatórias.

Steuermann começou a compor aos oito anos de idade, influenciado diretamente pelo gosto de sua mãe pelo lied. Como a prática musical era uma atividade normal na casa dos Steuermann, seu desenvolvimento musical foi bastante rápido. Uma grande predisposição para o piano, a possibilidade de contato com a produção musical para canto e o convívio com artistas e intelectuais que frequentavam as reuniões em sua casa, só contribuíram para seu crescimento como pianista e músico. Sua primeira apresentação pública foi um concerto beneficente aos nove anos de idade, quando acompanhou sua mãe em vários lieder, além de tocar peças para piano (STEUERMANN, 1922, Caixa 2).

Seus pais eram assinantes de um clube musical, o que proporcionou a Steuermann a possibilidade de entrar em contato com a produção musical mais recente: Strauss, Mahler, Buckner e Reger faziam parte de suas leituras cotidianas.

Consciente da necessidade que Edward tinha de intensificar seus estudos de piano, Augusta encaminhou-o a Vilem Kurtz. De origem tcheca, este pianista havia se estabelecido em Lemberg ${ }^{5}$, e era respeitado por sua seriedade e competência como músico e professor. Steuermann passou, a partir de 1904, a viajar regularmente para ter aulas com Kurz, o qual teve uma influência decisiva em seu desenvolvimento como pianista e como músico. O interesse pela composição já se fazia presente, e a grande facilidade de Steuermann em relação ao piano

\footnotetext{
${ }^{2}$ Augusta Steuermann chegou aos Estados Unidos em 1944 vinda da Polônia, passando por Moscou, Vladivostok e Seattle. Após sua chegada, escreveu um pequeno ensaio autobiográfico informal e inédito, que se encontra na Coleção Clara e Edward Steuermann na Biblioteca do Congresso de Washington.

${ }^{3}$ Seu nome de batismo era Salomea Sara Steuermann, mas Salka foi o nome que adotou e pelo qual era conhecida. ${ }^{4}$ Zygmunt Steuermann foi um dos mais renomados integrantes do Hasmonea Lwów, o mais importante clube de futebol judeu da Polônia. Integrou por duas vezes a Seleção Polonesa de Futebol. Foi assassinado pelos nazistas em 1941, ao tentar fugir do trem que o levaria a um campo de concentração. https://www.ynetnews.com/articles/0,7340,L-3931288,00.html (acesso em Outubro de 2021).

${ }^{5}$ Além de Lemberg, Kurtz lecionou também em Viena e no Conservatório de Praga. Entre seus alunos, além de Steuermann, pode-se se citar: Rudolf Firkusny, Artur Rodzinski, Stanislav Heller.
} 
levou-o a buscar uma literatura que estivesse de acordo com suas aspirações a um conhecimento musical mais amplo. Na verdade, pode-se dizer que o repertório estudado com Kurz foi pequeno em relação ao progresso proporcionado pela atividade musical desenvolvida por Steuermann em sua casa. Uma vasta literatura vocal estava disponível pela atuação de sua mãe como cantora; suas irmãs também tocavam, e não faltavam parceiros que vinham a sua casa para tocar a quatro mãos arranjos de música orquestral e de câmara, uma vez que partituras chegavam regularmente de Viena pelo correio. A habilidade que Steuermann desenvolveu em ler partituras à primeira vista impressionou muito os amigos e músicos que conviviam com ele nesta época.

Ao completar dezoito anos, e tendo terminado seus estudos no Ginásio em Sambor, Steuermann foi aconselhado por Kurtz a procurar outro professor, pois este achava que já havia feito tudo o que podia pela educação musical de seu aluno. E recomendou insistentemente a Steuermann que fosse procurar Ferruccio Busoni, que já era um professor de renome na época e ia, em agosto de 1910, a Basiléia para dar uma série de master classes. Steuermann, aceitando os conselhos de Kurtz, tocou várias vezes para Busoni. Segundo depoimentos do próprio Steuermann, suas aulas eram ao mesmo tempo magistrais e simples: ao tocar para Busoni a Sonata em Si menor de Liszt ele, depois dos costumeiros aplausos e do infalível beijo em sua testa, disse: "Eu vou tocar esta Sonata num concerto daqui a duas semanas. Você vai ver o que eu toco diferente de você" (ZANI NETTO, 1991, p. 17). Assim Busoni conduzia suas aulas com Steuermann. Os conselhos técnicos eram ocasionais, pois achava redundante discutir técnica pianística com alunos que, por sua grande habilidade, já haviam resolvido este problema. Steuermann comentaria, anos depois, esta postura de Busoni ao saber que ele, contraditoriamente, havia publicado vários volumes com exercícios técnicos extremamente complexos.

\section{Berlim e Viena}

Berlim era, no início do Séc. XX, um polo cultural efervescente e Busoni aconselhou insistentemente Steuermann a mudar-se para lá, por achar que seria o lugar ideal para seu desenvolvimento musical. Na verdade, Busoni não achava que Steuermann precisasse de aulas de piano, pois era um pianista já formado e maduro. Além do mais, estava ocupado demais com seus concertos e com suas composições. Era muito requisitado como pianista, mas teria preferido tocar menos e dedicar-se mais à composição. 
Steuermann não teve muitas oportunidades de mostrar suas composições para Busoni. Mas ao mostrar-lhe sua Sonata para Piano, Busoni encorajou-o a continuar compondo, mostrando-se evasivo quanto ao desejo de Steuermann em buscar um estudo formal de composição. Segundo Busoni, quando não existiam rédeas nem preconceitos, a liberdade de criação, por si só, seria o melhor caminho para o desenvolvimento de um compositor.

A insistência de Steuermann em continuar questionando Busoni não conduziu a nenhuma resposta para resolver seu problema. Steuermann decidiu-se então por procurar Engelbert Humperdinck ${ }^{6}$, compositor que lecionava na Academia de Berlim. Steuermann entendeu, finalmente, a relutância de Busoni quanto ao estudo de composição na Academia. Desejava aprender contraponto, o que parecia não agradar nada a Humperdinck, que não corrigia seus exercícios que eram, na verdade, harmonizações. Estas sim, ele corrigia, e se surpreendia ao ver seu aluno piorar em vez de melhorar. Humperdinck, entretanto, estava doente e desistiu de lecionar na Academia. Mas, mesmo antes disso acontecer, Steuermann havia chegado ao seu limite e desistiu de frequentar as aulas. Suas composições já o conduziam à atonalidade e à dissonância.

Busoni sugeriu então que Arnold Schoenberg poderia talvez ser um professor mais adequado. E certa noite, ao se reunirem em um restaurante após um concerto de Busoni, este pegou Steuermann pelo braço e levou-o a uma mesa onde estava Emil Hertzka, diretor da Editora Universal, acompanhado por um homem quase calvo e sua mulher, e disse: "Deixe-me apresentar-lhe o Sr. Steuermann, um aluno extremamente dotado e que gostaria de estudar com você". Schoenberg tirou sua agenda do bolso e disse: "Então, quando você gostaria de começar?". Pego de surpresa, Steuermann conseguiu gaguejar: "Na semana que vem". Este foi o início de uma relação que deveria se estender até a morte de Schoenberg em 1951. (STEUERMANN apud SCHULLER, 1964, p. 25).

Os encontros com Schoenberg eram quase que diários, e a proximidade com seus alunos permitia a construção de um diálogo que abordava suas próprias composições, e não a correção específica das peças de seus alunos. Seu foco era mais dirigido às questões estéticas e artísticas do que às técnico-musicais. Schoenberg havia terminado de escrever seu Harmonielehre e se dizia cansado dos pensamentos teóricos (STUCKENSCHMIDT, 1977, p.135). Várias vezes

\footnotetext{
${ }^{6}$ Humperdinck, compositor alemão nascido em 1854, escreveu várias óperas, sendo a mais conhecida Hänsel und Gretel, cuja estreia se deu em Weimar, sob regência de Richard Strauss. Lecionou na Academia de Artes de Berlin de 1911 a 1920.
} 
resolvia questões técnicas de escrita através de exemplos que buscava na literatura. Citava e mostrava trechos de filósofos como Schopenhauer, comparando a estrutura dos textos com a estrutura da obra musical.

Conhecer Schoenberg também foi, sem dúvida, o fator decisivo para o crescimento e a consolidação da carreira de Steuermann como pianista. O gosto e o entusiasmo de Steuermann em relação à música contemporânea, o entendimento da nova linguagem musical propiciado por sua própria atividade como compositor, a sua incrível facilidade em relação ao piano e, por que não dizer também, seu encantamento em relação à figura de Schoenberg, faziam dele o intérprete ideal da música de seu mestre (VIERTEL, 1969, p.56).

Steuermann começou imediatamente a apresentar as obras de Schoenberg em público: as Peças Para Piano op. 11, as Pequenas Peças op. 19; acompanhou ao piano as George-Lieder ou Das Buch der hängenden Gärten (O Livro dos Jardins Suspensos) op. 15 e fez uma redução para piano do Erwartung op.17. Talvez o maior desafio tenha sido para ele, na época, ensinar a Albertine Zehme a parte do Sprechgesang do Pierrot Lunaire. Steuermann tocou a parte de piano no conjunto instrumental que a acompanhou pela primeira vez na estreia desta peça, que causou muito impacto e grande escândalo (STEUERMANN apud SCHULLER, 1964, p.2235). Steuermann realizou turnês pela Alemanha, Áustria e Tchecoslováquia apresentando não apenas o Pierrot, mas as outras composições de Schoenberg.

Também em 1912, Steuermann encontrou Webern e Berg pela primeira vez. Webern estava morando em Zehlendorf, perto de Schoenberg, e Berg vinha regularmente visita-los. Estabeleceu-se entre eles uma relação extremamente forte, que tinha como centro a figura carismática de Schoenberg.

Clara Steuermann, que foi aluna de Schoenberg na UCLA - Universidade da Califórnia Los Angeles - comentaria, muitos anos depois:

Schoenberg exercia uma enorme influencia em qualquer pessoa que se aproximasse dele. [...] minha vida musical transformou-se a partir da primeira aula que tive com ele.... Schoenberg possuía sem dúvida uma personalidade contundente. Não posso dizer se positiva ou negativa; era extremamente forte e dependendo da potência do caráter da outra pessoa, poderia impactá-la com maior ou menor intensidade (SMITH, 1979-1980, p. 265).

Webern e Berg ficaram igualmente impressionados com a habilidade de Steuermann ao piano, e a partir de então, pode-se dizer que Steuermann passou a ser o "pianista oficial" do grupo. Webern era também um ótimo pianista e havia feito com Schoenberg um arranjo de suas Cinco Peças para Orquestra para dois pianos a oito mãos. Steuermann tocava em um dos pianos 
com Louis Closson, um aluno de Busoni; e Webern no outro com Louis Gruenberg. As apresentações deste tipo de música eram consideradas uma heresia, e encontraram sempre uma grande oposição por parte do público ${ }^{7}$.

Schoenberg precisava da colaboração de alguém que solucionasse o problema que, então, parecia ser o mais importante: como resolver, técnica e musicalmente, a interpretação de sua obra para piano. Um estudo pianístico especializado, minucioso e aprofundado se fazia necessário: as melodias caracterizavam-se por grandes intervalos e por uma aparente descontinuidade; o ritmo era intrincado, pelo uso de uma variedade enorme de sutilezas de acentuação que mascaravam os tempos fortes; havia o problema da sonoridade, que além de pedir um equilíbrio perfeito, exigia um estudo altamente especializado de pedalização (STEUERMANN, 1989, p.183). As indicações de Schoenberg nas partituras eram tão numerosas que beiravam o exagero. E Steuermann se apresentou como a figura ideal não somente para desvendá-las, como também para divulgá-las. Esta foi uma tarefa à qual se empenhou, desde então, até o fim de sua vida ${ }^{8}$.

As atividades musicais de Steuermann foram interrompidas bruscamente pela I Guerra Mundial. Seu desejo de se alistar no exército austríaco, apesar da oposição de sua família, era bastante forte. Mas uma pequena deficiência visual impediu-o de realizar este desejo. Ao ser rejeitado pelo exército, apresentou-se na Legião Polonesa e foi designado para servir no escritório do Oficial de Saúde em Przemysl, uma cidade austríaca no sudeste da Polônia, nos Montes Cárpatos. Seu superior sentiu-se extremamente envaidecido por ter entre seus subordinados um grande pianista; e como era um músico amador, providenciou um piano para que Steuermann pudesse manter suas atividades musicais. Neste período Steuermann trabalhou na redução de duas obras de Schoenberg: a parte instrumental da Glückliche Hand ${ }^{9}$ op. 18 (A Mão do Destino) e a Sinfonia de Câmara n.1 op. 9 para piano solo.

\footnotetext{
${ }^{7}$ O primeiro ensaio desta obra se deu em 23 de janeiro de 1912. Schoenberg escreveu em seu diário: "Grande decepção. Meus alunos são melhores que os de Busoni? Eles são melhores músicos e acredito também que sejam pessoas mais inteligentes. Gruenberg é especialmente muito ruim. ... não tem ritmo. É difícil ensaiar algo assim. Fica difícil para mim dizer se estão juntos. Sinto falta dos sons! Das cores! O piano é, afinal das contas, apenas um instrumento. Mas menos para músicos do que para pianistas. Seria esta a razão de ser tão popular?" (STUCKENSCHMIDT, 1977, pag. 156).

${ }^{8}$ Em 1966, a Editora Universal iniciou a publicação da Edição Completa da obra de Arnold Schoenberg. O volume contendo sua obra integral para piano foi editado por Edward Steuermann, mas lançado apenas em 1968, quatro anos após a sua morte.

${ }^{9}$ Versão para Dois Pianos, Coro e Solista. Esta obra foi apresentada em primeira audição no Brasil pelos autores deste artigo, com o Coral da OSESP e regência de Naomi Munakata. Sala São Paulo, SP, 31 de outubro de 2004.
} 
As folgas do exército eram passadas na casa da família, em Wychylowka, que tinha sido em parte requisitada pelo exército e transformada em quartel general. Rosa e Salka, suas irmãs, haviam se tornado enfermeiras da Cruz Vermelha. Mas logo toda a família foi obrigada a se refugiar em Viena, pois o exército russo havia tomado a Galícia. Edward realizou concertos para a Cruz Vermelha, Rosa foi para Hamburgo para continuar seus estudos de teatro, e Salka permaneceu em Viena. Na primavera de 1915 as forças germânicas expulsaram os russos da Galícia e os Steuermann puderam voltar para sua casa a qual, conforme diria Salka anos mais tarde, havia sido menos poupada pelos ratos do que pelos bombardeios dos exércitos (VIERTEL, 1969, p.70).

Ao se desligar do exército, com o fim da guerra, Edward Steuermann decidiu fixar-se em Viena, onde iria permanecer até 1936. Os anos de guerra haviam aproximado Edward de Webern, Alexander von Zemlinsky (cunhado de Schoenberg), Rainer Maria Rilke, Franz Kafka e Karl Kraus. Schoenberg estava morando em Mödling, perto de Viena; Berg também mudouse para Viena; Webern estava sempre perto de Schoenberg. E Rudolph Kolisch ${ }^{10}$, violinista que se tornaria um grande amigo de Steuermann, iniciava também seus estudos com Schoenberg. A Segunda Escola de Viena havia se definido.

O confronto com a realidade do final da guerra, em 1918, não foi fácil. A situação era desastrosa, a inflação conduziu todos a um estado de miséria. Mesmo assim, a magnitude que a sociedade alemã atribuía à atividade musical reforçou a reputação dos alemães como "um povo musical". A Alemanha já havia produzido compositores, regentes e interpretes notáveis. Havia criado conservatórios que atraiam estudantes de vários países, e abrigava mais orquestras e casas de ópera do que qualquer outra localidade do mundo (APPLEGATE, POTTER, 2002, p.21). Foi neste cenário que Schoenberg, "sempre cheio de ideias" segundo Steuermann, idealizou a "Sociedade de Apresentações Musicais Particulares"11.

A "Sociedade" foi a primeira a se dedicar à música do Século XX, e sua proposta era clara: os concertos eram dedicados às pessoas que se filiavam e o pagamento variava de acordo com a situação financeira de cada sócio. Estes deveriam ir às apresentações, cujo programa só era dado a conhecer na hora. Não era permitido aplaudir nem fazer qualquer espécie de

\footnotetext{
${ }^{10}$ Rudolph Kolish, violinista, foi responsável por inúmeras primeiras audições de compositores da música do Século XX, incluindo Bartok, Debussy, Alban Berg e Schoenberg, de quem foi aluno. Foi fundador do Kolish Quartet, inicialmente conhecido como Neues Wiener Streichquartett, e mais tarde como Pro Arte Quartet. Sua irmã, Gertrud, iria se tornar a segunda esposa de Arnold Schoenberg.

11 Os autores do artigo optaram por esta tradução para o português: do alemão: Verein für Musikalische Privataufführungen, do inglês: Society for Private Musical Performances.
} 
comentário a respeito das obras apresentadas, a fim de não deixar que qualquer pressão por parte da plateia viesse a resultar em críticas ou julgamentos. (SHAWN, 2003, p.177). O primeiro concerto foi um evento histórico: Steuermann tocou a Primeira e a Quarta Sonatas de Scriabin e um arranjo da Sétima Sinfonia de Mahler para piano a quatro mãos com Bachrich ${ }^{12}$, sob regência de Schoenberg. Entre 1918 e 1921, foram realizados 113 concertos na Sociedade. (STEUERMANN apud SCHULLER, 1964, p.23).

Havia uma hierarquia para supervisionar as apresentações da "Sociedade": Berg, Webern, Steuermann, e posteriormente Erwin Stein ${ }^{13}$, davam suporte às apresentações, mas a autoridade principal era a de Schoenberg.

Nos concertos da "Sociedade", Steuermann tocou as Elegias e as Sonatinas de Busoni; Gaspard de la Nuit, de Ravel; a Sonata de Berg, a Piano Rag Music e as Easy Pieces (para piano a quatro mãos) de Stravinsky. Com Rudolph Serkin, tocou também um arranjo de Petroushka, para piano a quatro mãos. Foi o primeiro a tocar, na "Sociedade" e posteriormente em turnês, o Primeiro Caderno dos Estudos de Debussy. Havia também concertos da "Sociedade" realizados especialmente para editoras de música, com leituras de partituras de inúmeros compositores. Steuermann tocou a Sonata de Ludwig Zenk ${ }^{14}$ para a Editora Universal, que a publicou. Arrependeu-se amargamente, anos depois, ao descobrir que Zenk havia se tornado um nazista convicto (ZANI NETTO, 1991, p.28).

A maior dificuldade para a "Sociedade" era contratar instrumentistas. Schoenberg insistia sempre em pagar os músicos, o que tornava as apresentações quase sempre impossíveis de serem realizadas como todos gostariam.

Steuermann, quando necessário, fazia reduções de partes instrumentais e tocava num grande harmônio, comprado para suprir a falta de músicos.

Na década de 1920, Steuermann encontrou vários compositores: Milhaud, Hindemith, Poulenc, Ravel. Alma Mahler ofereceu uma recepção para Poulenc e Millhaud, que havia regido uma apresentação do Pierrot Lunaire em Paris. Nesta ocasião, Steuermann tocou seu arranjo da Sinfonia de Câmara $n^{\circ} 1$ op.9 de Schoenberg e este regeu uma apresentação do

\footnotetext{
${ }^{12}$ Esrnst Bachrich - compositor, regente e pianista austríaco. Aluno de Schoenberg, regeu a Opera do Povo em Viena e foi um dos organizadores da série de concertos "Musica do Presente". Foi morto pelos nazistas no campo de concentração de Lublin, na Polônia, em 1942.

${ }^{13}$ Erwin Stein - regente e musicólogo austríaco, foi um dos primeiros alunos de Schoenberg. Trabalhou como editor para a Editora Universal em Viena, e posteriormente para a Boosey \& Hawkes em Londres.

${ }^{14}$ Ludwig Zenk estudou Teoria e Composição com Anton Webern de 1921 a 1925 e regência com Hermann Scherchen. Foi secretário da Sociedade Internacional de Música Contemporânea.
} 
Pierrot. Milhaud respondeu regendo partes daquela obra, para mostrar a Schoenberg sua própria versão. Para Steuermann, o fato mais marcante deste encontro foi, entretanto, o convite que Milhaud e Poulenc lhe fizeram para que jantassem no Hotel Brístol. Era 1920, e quase não havia comida em Viena por causa da inflação. Steuermann comentaria, anos mais tarde, que esta havia sido sua primeira refeição decente daqueles últimos anos (STEURMANN apud SCHULLER, 1964, p.22-35). O encontro com Ravel aconteceu mais ou menos na mesma época. Os dois tocaram, também na casa de Alma Mahler, a versão para piano a quatro mãos de Ma Mère L'Oye e da Rhapsodie Espagnole para o regente Oskar Fried ${ }^{15}$, que pretendia fazer um concerto com obras de Ravel e sempre gostava de ouvir antes as obras executadas ao piano. Ravel impressionava muito os compositores da Escola de Viena, especialmente Webern, que adorava as Canções Mallarmé, por achar que eram próximas às ideias de Schoenberg.

Mas, ainda naquele ano, Schoenberg partiu para a Holanda e a "Sociedade", sem seu idealizador, perdeu a força e não conseguiu manter sua programação com o mesmo nível de assiduidade nem de frequência (McCOY, 1999, p. 6). Pouco a pouco foi se extinguindo, até parar completamente suas atividades em 1923.

A finalidade inicial da Sociedade havia completado seu proposito: apresentar e divulgar a produção musical contemporânea através de apresentações planejadas e de qualidade, exaustivamente ensaiadas. Um aspecto de inegável importância foi o ganho pedagógico resultante da participação dos jovens músicos nas suas atividades: organizar apresentações, programar os ensaios, recrutar músicos, fazer arranjos das mais variadas obras para as mais inusitadas formações instrumentais. (CALICO, 2010, p.143).

Steuermann continuou a se apresentar com Rudolph Kolisch em concertos que privilegiavam a produção musical contemporânea. Mas mesmo assim, suas carreiras começaram a seguir caminhos diferentes. Steuermann dedicou-se a construir sua carreira como pianista e também como professor. Os laços de amizade que o ligavam a Kolisch permaneceram inalterados, embora ambos se mantivessem afastados por muito tempo e somente viessem a se reencontrar anos mais tarde nos Estados Unidos. Durante anos se corresponderam através de cartões postais, que continham no final lances de xadrez, outra paixão que os unia (STEUERMANN, 1982, Caixa 4).

\footnotetext{
${ }^{15}$ Oskar Fried - Regente e compositor alemão, estudou com Engelbert Humperdink e foi o primeiro regente a gravar uma Sinfonia de Gustav Mahler, de quem era grande admirador. Tornou-se cidadão soviético em 1940.
} 
Os verões continuaram a reunir a família em Sambor ou nas Montanhas Tatra, nos Alpes Austríacos. Salka havia se casado com Berthold Viertel, escritor, poeta e dramaturgo. Rosa também havia se casado com um diretor de teatro, Josef Gielen, pessoa de grande projeção nos meios intelectuais europeus.

Durante os anos de 1922 a 1936, Steuermann empenhou-se ao máximo em se projetar como pianista. Os programas de concertos, críticas, e sua correspondência, são prova de seus esforços nesse sentido. Mesmo sem a ajuda de um empresário, suas apresentações eram cada vez mais numerosas e suas viagens pela Europa cada vez mais frequentes. Apesar de ter seu nome associado aos músicos da Segunda Escola de Viena, de se dedicar à divulgação da música de seu tempo, o repertório de Steuermann era muito extenso e incluía a música do passado com a mesma intensidade que dedicava à música contemporânea.

Uma grande amizade com Edward Clark, um ex-aluno de Schoenberg que após a guerra fora contratado pela $\mathrm{BBC}$ de Londres, permitiu que Steuermann viajasse inúmeras vezes à Inglaterra para gravar apresentações para o Terceiro Programa da $\mathrm{BBC}$, o qual era dedicado à música erudita e transmitido para toda a Europa, com grande audiência.

Steuermann, durante os anos vinte, viajava regularmente a Praga para dar aulas de piano. Mas foi aos poucos diminuindo essa atividade, uma vez que era cada vez mais requisitado pelos compromissos de sua carreira de pianista. Fez várias turnês para apresentar o Pierrot Lunaire, tendo como solista Marya Freund ${ }^{16}$ ou Erika Stiedry-Wagner ${ }^{17}$. E durante algum tempo excursionou com um trio por cidades da Itália, França e Espanha.

O início efetivo de sua carreira como professor foi em 1932, quando concordou em lecionar em duas escolas de música na Polônia. Viajava duas vezes por mês para dar aulas. Além disso, começou também a lecionar em Viena. Em 1936, com a ameaça da ascensão crescente do Nazismo, Steuermann começou a pensar seriamente em deixar a cidade. A Academia de Música de Viena ofereceu-lhe a oportunidade de lecionar, mas ele negou.

\footnotetext{
${ }^{16}$ Cantora, nasceu em Breslau, Polônia, em 1876. Interprete de seus contemporâneos, estreou os Gurrelider de Schoenberg em 1913 e também realizou a Sprechstimme das primeiras apresentações do Pierrot Lunaire em francês e inglês.

17 Cantora e atriz, foi a intérprete considerada ideal por Schoenberg para substituir Albertine Zehme na Sprechstimme do Pierrot Lunaire. Juntamente com Steuermann e Rudolf Kolish, participou da gravação histórica feita em 1940 em Nova Iorque, regida pelo próprio Schoenberg. Referência: Masterworks Portrait - MPK 45695. CBS, Europe, 1989.CD.
} 
Heinrich Neuhaus ${ }^{18}$, seu amigo dos tempos de estudante em Berlim e que lecionava no Conservatório de Moscou, havia recebido um convite para lecionar também no Conservatório de Kiev, na Rússia, e convidou-o para assumir master classes e dar concertos. Além disso, a irmã de Steuermann, Salka Viertel, que já vivia nos Estados Unidos há bastante tempo, insistia muito para que fosse encontra-la. Por mais singular que possa parecer, a razão pela qual Steuermann optou em ir para a América deve-se exclusivamente ao fato de o passaporte para os Estados Unidos haver chegado antes da permissão para viajar para a Rússia. Bastante preocupado com a incerteza do futuro que o aguardava, Steuermann partiu para a América, após uma escala em Londres aonde gravou um programa na BBC (STEUERMANN, 1989, p. 17).

\section{Estados Unidos}

Edward Steuermann chegou nos Estados Unidos, mais precisamente em Nova Iorque no fim de maio de 1936 com Margaret, sua filha, que tinha então 11 anos de idade. Margaret Steuermann nasceu em 12 de julho de 1925 e faleceu recentemente em Nova Iorque em 18 de novembro de 2021. Sua mãe, Hilda Merinsky, havia sido aluna de Edward. Casaram-se em 1922 e se separaram em 1927 (BERG, 2016, p. 282).

Após passar alguns dias hospedado na casa de amigos, Steuermann foi para Los Angeles onde, após muitos anos, reencontrou sua irmã Salka, que já morava nos Estados Unidos desde 1928. Passando de atriz a roteirista em Hollywood, havia alcançado reconhecimento por ter escrito os roteiros de vários filmes de Greta Garbo, de quem era amiga: Ana Karenina e Rainha Cristina estavam entre eles (RIFKIND, 2020, p.263).

A casa de Salka, em Mabery Road, havia se tornado um verdadeiro centro de recepção às pessoas que chegavam à América. Artistas e intelectuais que começaram, como Edward, a imigrar para os Estados Unidos fugidos do nazismo, sempre encontraram em Salka o apoio, a amizade e o carinho para começarem uma nova vida. Muitos deles eram convidados a fazer parte do corpo docente das universidades americanas e o Departamento de Imigração tinha, como única exigência para conceder um visto de permanência no país, o domínio do idioma. Geralmente esta exigência era burlada pela influência das próprias universidades, mas quando isto não acontecia, havia a necessidade de se aprender a língua e submeter-se a um exame. Salka

\footnotetext{
${ }^{18}$ Pianista e professor de origem alemã e polonesa. Lecionou no Conservatório de Moscou de 1922 a 1964. Entre seus alunos estão: Sviatoslav Richter, Emil Gilels, Radu Lupo. Seu livro “A Arte de Tocar Piano" tornou-se um clássico da temática da técnica pianística.
} 
conhecia inúmeras personalidades que trabalhavam na indústria cinematográfica: atores, produtores, diretores, roteiristas. Pode, assim, colocar vários de seus protegidos nas casas destas pessoas para trabalharem como motoristas, governantes, secretários. Era uma maneira eficiente de proverem seu sustento e aprenderem inglês rapidamente, a fim de obterem o visto de permanência (ZANI NETTO, 1991, p.34).

Os meses que Steuermann passou em Los Angeles foram marcados por uma grande inatividade musical. Schoenberg também estava morando na Califórnia, uma vez que havia emigrado para os Estados Unidos em 1933. Poucos recitais foram marcados em São Francisco e Los Angeles. O único concerto importante foi uma apresentação do Primeiro Concerto de Beethoven para piano e orquestra sob a regência de Otto Klemperer, no Hollywood Bowl, que obteve enorme sucesso (RIFKIND, 2020, p.181). Era urgente a necessidade de sair em busca de melhores oportunidades. Por mais que sua irmã Salka insistisse para que ficasse na Califórnia, Steuermann decidiu mudar-se para Nova Iorque. Aí moravam velhos amigos: Mark Brunswick e Roger Sessions. Antigos alunos, europeus que haviam imigrado antes dele (Fritz Jahoda e Irwing Wassermann), e até mesmo americanos que haviam estudado com ele na Europa, moravam em Nova Iorque e provavelmente poderiam indicar-lhe novos alunos. Mas a incerteza era muito grande (ZANI NETTO, 1991, p.34).

Sua primeira apresentação em Nova Iorque aconteceu em 1937, no Town Hall. As cartas escritas para seus familiares e amigos comprovam quão duros foram seus primeiros anos naquela cidade (STEUERMANN, 1982, Caixa 2). Sua irmã Rosa havia mudado para Buenos Aires com seu marido, Josef Gielen e seus dois filhos, Michael e Carola. Michael Gielen, que mais tarde viria a se tornar músico e regente de reconhecimento internacional era, como dizia Steuermann, o único membro de sua família que se interessava por música na época, e a correspondência entre eles era intensa. O interesse e o gosto de Michael pela música contemporânea foram grandemente incentivados por Steuermann. Michael Gielen dedicou-se, enquanto regente, a divulgar a produção musical do Século XX.

Durante anos, Steuermann não teve sequer um lugar seu para morar. Alugava parte de apartamentos de pessoas amigas e não tinha nenhuma espécie de mobília; apenas um piano, nem sempre de cauda, também alugado. Um convite para apresentar uma série de palestras e conferências sobre pedagogia pianística na New School, em 1944, não teve o retorno que pretendia. Acreditava que esta seria uma boa oportunidade para que algumas portas se abrissem e que suas expectativas em divulgar sua atuação como compositor e intérprete se 
concretizassem. Mas a desorganização da divulgação fez com que ninguém se inscrevesse, e o evento foi cancelado. Por outro lado, músicos que o tinham conhecido na Europa aconselhavam alunos a procurá-lo e sua reputação como professor foi se firmando cada vez mais.

Um grande acontecimento marca o inicio do ano de 1944: em 06 de fevereiro Steuermann estreou o Concerto para Piano e Orquestra op.42 de Schoenberg, sob regência de Leopold Stokowski ${ }^{19}$. O concerto, patrocinado pela General Motors, foi transmitido pela NBC em rede nacional e teve grande repercussão (STUCKENSCHMIDT, 1977, p. 465). No mesmo dia, Schoenberg envia a Steuermann o telegrama que se vê a seguir:

Figura 1: Telegrama de Schoenberg cumprimentando Steuermann pela estreia do Concerto para Piano Op. $42^{20}$.

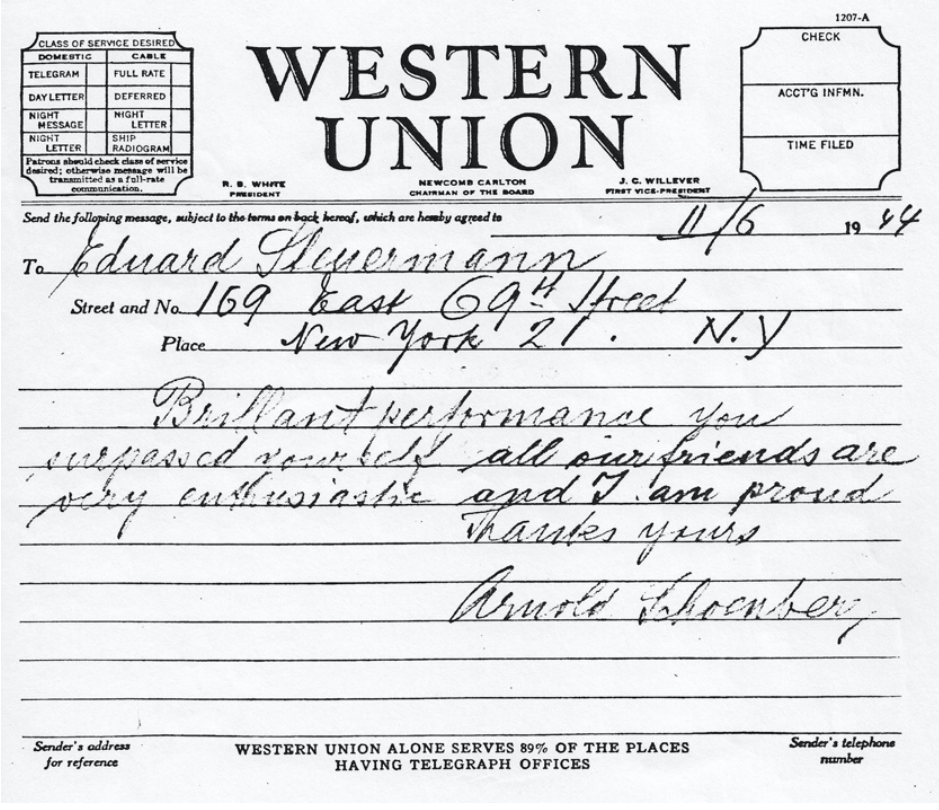

Fonte: STEUERMANN, C., 1982, Caixa 7.

Poucos dias depois, Steuermann recebeu uma carta de uma aluna de Schoenberg: (STEUERMANN, C.,1982, Caixa 7).

Caro Sr. Steuermann:

Durante os últimos três anos tive o privilégio de estudar com seu colega e amigo, Arnold Schoenberg, na Universidade da Califórnia em Los Angeles, e tenho inclusive sido sua assistente. Em menos de duas semanas eu pretendo completar os créditos para conseguir o título de Mestre de Artes em Música. Já estudei piano, mas à medida que as aulas com o Sr. Schoenberg foram ficando mais complexas, eu achei que não era mais possível continuar estudando seriamente piano e ao mesmo tempo os problemas teóricos da

\footnotetext{
19 A gravação original pode ser encontrada em: https://soundcloud.com/daniel-plante-511223801/schoenbergpiano-concerto-op-42-1944-02-06-nbc-stokowski-steuermann-wpbroadcast (Acesso em Outubro de 2021).

20 "Interpretação brilhante você se superou todos nossos amigos estão extasiados e eu estou orgulhoso. Obrigado, sinceramente. Arnold Schoenberg” (Tradução nossa).
} 
música; [...] deveria tomar uma decisão, então eu achei que o trabalho com os Sr. Schoenberg era precioso e necessário demais para ser levado superficialmente. Entretanto, meu propósito agora é voltar ao piano e dedicar meu tempo recuperando a familiaridade com o teclado, mas ainda mais, tornar-me uma pianista 'musicista'.

A carta era de Clara Silvers, e foi escrita em Los Angeles no dia 18 de fevereiro. Depois de uma breve apresentação, ela revela seus planos de mudar-se para Nova Iorque com o proposito de continuar seus estudos de piano e tornar-se sua aluna.

[...] O Sr. Schoenberg, ao conversarmos sobre os planos para meus estudos futuros, recomendou-me o Sr. como sendo a única pessoa com quem poderia alcançar meus objetivos. Isto me agradou bastante porque eu já queria há muito tempo estudar com o Sr. - o que até agora não foi possível por causa de meu trabalho na Universidade.

Eu pretendo chegar em Nova Iorque em março. Se o Sr. não estiver muito ocupado, eu gostaria muito de encontrá-lo e conversar com o Sr., esperando que possa aceitar-me como sua aluna (Ibid.).

E encerra, informando que na carta há um recado de Schoenberg (manuscrito), apresentando-a e fazendo um breve relato de suas atividades, além de situar duas de suas amigas que estavam estudando com Steuermann.

[...] Segue junto com esta carta um bilhete do Sr. Schoenberg, que poderá lhe dar uma ideia de minha formação. Também, em Nova Iorque, mora uma amiga minha e colega de universidade, Anni Bergmann, que poderá lhe dar informações a meu respeito. Ela trabalhou um pouco com sua mulher. Também Ada Kopetez ${ }^{21}$, que é sua aluna atualmente.

É difícil expressar em uma carta o que significa para mim trabalhar com um grande músico como o Sr. Ficaria grata se o Sr. me respondesse se é possível, e quando poderia encontrá-lo depois que chegar a Nova Iorque (Ibid.).

Na sequência, na mesma carta, encontra-se o recado manuscrito de Schoenberg que pode ser lido a seguir:

\section{Querido Steuermann:}

Eu já lhe falei a respeito da Srta. Silvers. Ela tocou a minha Sinfonia de Câmara n. II para dois pianos, com o Sr. Stein, muito bem. Ela é muito musical e estudou bastante contraponto e composição. Foi também minha assistente em aulas e se saiu muito bem. Acho que você gostará muito de conhecê-la.

Um abraço, Arnold Schoenberg.

\footnotetext{
${ }^{21}$ Ada Kopetez nasceu em Nova Iorque e foi aluna de James Friskin e Edward Steuermann. Lecionou na Manhattan School of Music e na Columbia University.
} 
Figura 2: Bilhete manuscrito de Schoenberg a Steuermann na carta de Clara Silvers.

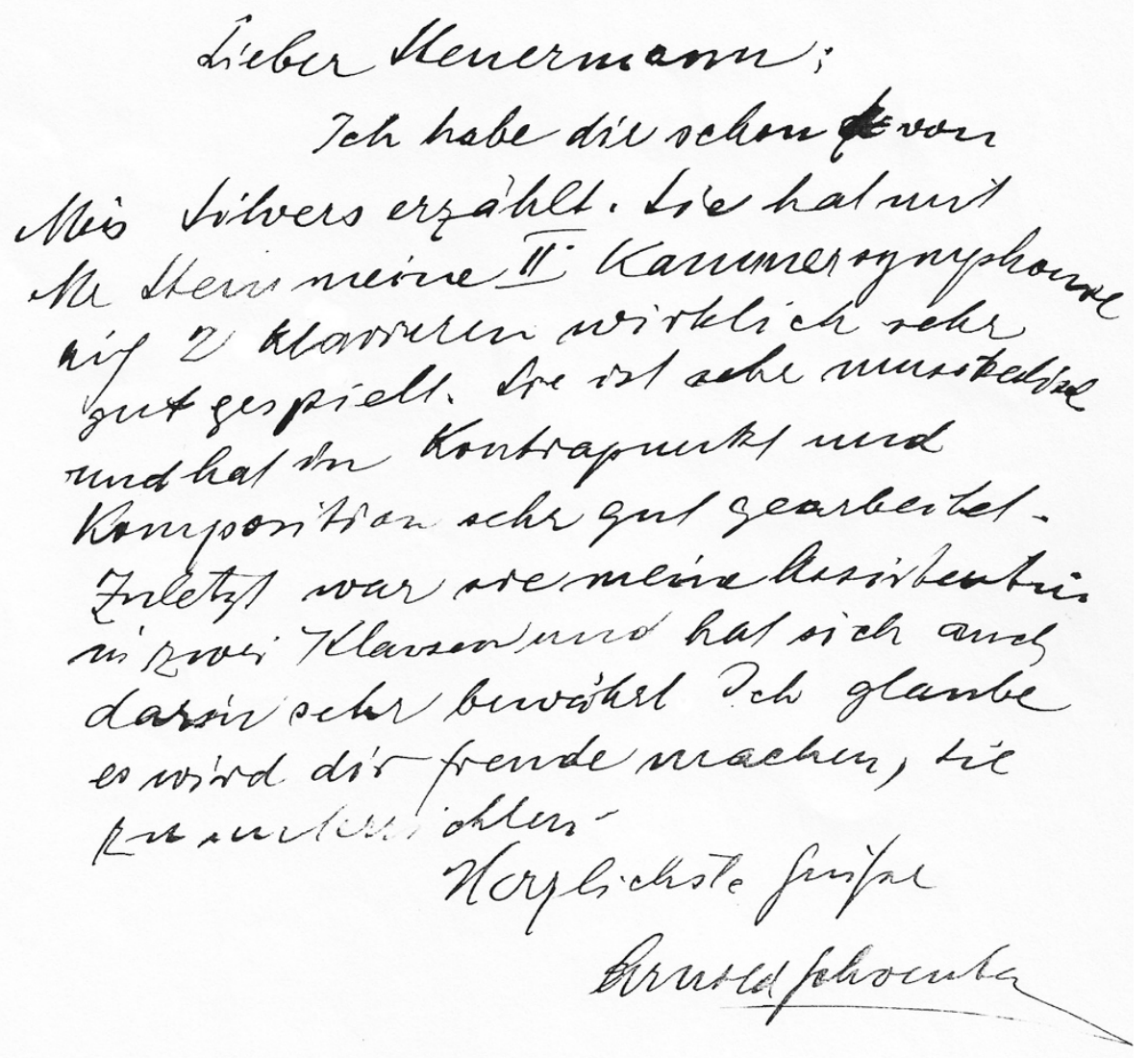

Fonte: STEUERMANN, C., 1982, Caixa 7.

Clara Silvers chegou a Nova Iorque na primavera de 1944, e imediatamente começou a ter aulas de piano com Edward Steuermann. Encontrou-o morando como inquilino de Elissa Landi $^{22}$, apenas com seu piano. Clara era uma mulher extremamente ativa e dinâmica e logo começou a se preocupar com Steuermann, a cuidar de sua vida e de sua carreira. Ela conseguiu convencê-lo a alugar um pequeno apartamento na West $73 \mathrm{rd}$. Street, no outono do ano seguinte. Finalmente iria ter condições de se estabelecer em um lugar onde pudesse organizar sua vida, seus pertences; ter um instrumento para estudar, compor e dar aulas, além de receber seus alunos e amigos. Foi o primeiro lugar que pode chamar de casa desde que saíra da Europa, nove anos atrás.

No mesmo ano em que Clara chegou a Nova Iorque, Steuermann convidou-a a fazer o curso de verão no Black Mountain College, perto de Asheville, na Carolina do Norte, onde havia sido convidado a lecionar. Foi uma experiência que nunca mais saiu de sua memória, pois jamais conhecera em sua vida um músico com tanta sensibilidade, tanto talento e tanto

\footnotetext{
${ }^{22}$ Elissa Landi foi uma atriz italiana, popular nos filmes de Hollywood nos anos de 1920 e 1930.
} 
conhecimento. Além disso, em Black Mountain ela pôde encontrar e conhecer outros músicos como Rudolph Kolisch e Gunther Schuller que eram para ela, juntamente com Steuermann, "músicos que abriam as portas", o que em seu entender significava pessoas de visão ampla e libertas de preconceitos. Estas eram as pessoas que para Edward e Clara se tornaram uma espécie de família, e que assim permaneceram por toda a vida.

$\mathrm{O}$ ano seguinte também possibilitou a Steuermann uma experiência didática inédita: participar do curso de verão realizado no Instituto de Música do Kennyon College de Gambier, Ohio. Era uma proposta inédita, de realizar um curso cujo objetivo principal era substituir qualquer rigidez curricular por cursos livres, audições públicas e master-classes, onde qualquer pessoa poderia participar, conviver com os músicos e discutir em grupos quaisquer questões que fossem levantadas. Através desse curso Steuermann começou a ter seu nome reconhecido como um grande professor de piano (ZANI NETTO, 1991).

Ao mesmo tempo que estudava com Steuermann, Clara trabalhava como editora musical e era o principal contato entre Schoenberg e seus editores. A obra de Schoenberg editada nos Estados Unidos, tanto as partituras quanto os livros, devem a Clara todos os estágios de realização, desde as revisões até sua publicação.

Steuermann passou a dedicar-se cada vez mais à atividade pedagógica, pela necessidade de prover seu sustento. A partir de 1948, passou a dar aulas na Juilliard School de Nova Iorque, nos cursos de verão.

Em 1948, Steuermann foi também convidado para lecionar no Conservatório de Música de Filadélfia, que é o conservatório mais antigo dos Estados Unidos. Olga Samaroff ${ }^{23}$, que lecionara naquela instituição por tantos anos, havia falecido; seu lugar estava vago e era necessário que alguém a substituísse. Um de seus ex-alunos, que também havia estudado com Steuermann, apresentou-o a Maria Ezerman Drake, Diretora do Conservatório, e a partir de então, até 1964, Steuermann viajou regularmente à Filadélfia para lecionar.

Pianistas que se tornaram importantes interpretes, como Lili Krauss, Moura Limpany, Alfred Brendel, Augustin Anievas, Joan Rowland, Jacob Gimpel, Russell Shermann, David Porter, Menahem Pressler, Jacob Maxim, foram seus alunos (Ibid.).

Mas desde sua chegada a Nova Iorque, Steuermann estava, de certa maneira, isolado e se perguntava se não deveria ir para Los Angeles, aonde estavam seus companheiros de Europa:

\footnotetext{
${ }^{23}$ Pianista, crítica musical e professora. Foram seus alunos: Rosalyn Tureck, William Kapell, Alexis Weissenberg.
} 
Schoenberg, Thomas Mann, Hanns Eisler e Bertold Brecht. Também os convites e oportunidades de se apresentar como pianista eram raros, uma vez que as pessoas ligadas a Schoenberg não eram muito bem vistas, em grande parte pela rivalidade criada entre os alunos e apoiadores de Schoenberg e os de Stravinsky. Tal polaridade era mais motivada pela atitude rígida de Schoenberg, que chegava a proibir que seus alunos fossem a concertos que apresentassem obras de Stravinsky (NEWLIN, 1980, pg.301). Constituíram-se assim dois polos: Schoenberg/ Roger Sessions e seguidores do dodecafonismo de um lado, Stravinsky/ Aaron Copland e neoclássicos, de outro. Também a divulgação e apresentação da produção dos compositores do círculo de Schoenberg foram extremamente prejudicadas pelo fato das partituras editadas pela Editora Universal de Viena não estarem disponíveis por mais de uma década, desde a invasão da Áustria por Hitler, em 1938.

Esta realidade se modificou apenas quando Dimitri Mitropoulos assumiu a direção da Filarmônica de Nova Iorque em 1949, quando Steuermann e seu circulo de interpretes e compositores passaram a ser mais aceitos e respeitados e ter acesso às principais salas de concerto de Nova Iorque. (SCHULLER apud NEWSON, 1995).

O relacionamento entre Edward Steuermann e Clara Silvers foi se tornando cada vez mais intenso e eles se casaram em 1949.

O casamento fez com que Clara mergulhasse completamente no mundo de Steuermann. De repente ela se viu no meio de personalidades que a fascinavam: Ernst Krenek, Bertold Brecht, Gerhard e Hanns Eisler, Thomas e Heinrich Mann, Martha Graham, sem mencionar os amigos de Salka Viertel, que encontravam quando podiam passar as férias de verão em Santa Mônica: Greta Garbo, Ernst Lubitsch, Fred Zinnemann e tantos outros. Em 1951, ano da morte de Schoenberg, Clara deixou o lugar onde trabalhava e se tornou assistente de administração no Juilliard Opera Theater. Permaneceu neste cargo até 1956, quando nasceu sua primeira filha, Rebecca. Os estudos de piano já haviam sido colocados em segundo plano desde o início de seu casamento, pois suas energias estavam totalmente voltadas para a vida e a carreira de Edward.

Todo esse período havia sido bastante fértil para Steuermann no que diz respeito às suas composições: as Canções Brecht (1945); as Sete Valsas para Quarteto de Cordas (1946); a Suíte para Piano (1949-1951); o Trio para Violino, Violoncelo e Piano (1954); a Improvisação e Allegro para Violino e Piano (1955) e as Variações para Orquestra (1958), foram todas escritas nestes anos. Além disso, em 1952, Steuermann havia recebido a Medalha Schoenberg, a maior 
honraria concedida pela Sociedade Internacional de Música Contemporânea, em Salzburg, por suas atividades em promover e aprofundar a compreensão das obras musicais contemporâneas.

Compor não é um hobby para mim, mas sim o lado mais importante da minha personalidade artística. Quando eu tenho tempo livre, eu tento compor; é meu impulso mais forte e me mantém vivo. Aos domingos, uma ou duas manhãs por semana... O tempo passa tão depressa. Como eu sempre vivi com pressa, é difícil para mim testar ideias, deixá-las amadurecer, etc. É tão difícil trabalhar com interrupções: às vezes eu me transformo numa espécie de Penélope musical e rasgo o que escrevi anteriormente... Se Mahler escreveu novelas, eu penso mais em termos de um diário. Quando me sinto incapaz de compor, eu me lembro do que se falava de Webern: que ele conseguia compor silêncios. Então eu tento fazer isso também" (STEUERMANN,1989, p.67).

Steuermann manteve-se sempre fiel aos ensinamentos de Schoenberg, e sua obra testemunha seu comprometimento e empenho em desenvolver os princípios da escrita dodecafônica.

Steuermann acreditava que se Schoenberg não tivesse ficado tão doente nos últimos anos de sua vida, Schoenberg poderia ter desenvolvido as implicações harmônicas da composição dodecafônica. Ao dividir a série dodecafônica em hexacordes, pode-se estabelecer zonas harmônicas: utilizando partes da serie, excluindo determinadas notas, usando então essas mesmas notas em momentos crucias para produzir um efeito cadencial, uma modulação. O próprio Steuermann trabalhou nessa direção e sentiu que Schoenberg - que sempre se identificou mais na longa linha da tradição do que como revolucionário - estava se movendo também nessa direção (STEUERMANN, C. apud SMITH, 1979-1980, p. 262).

O depoimento de Clara reforça, certamente, o testemunho de Gunther Schuller ${ }^{24}$ ao afirmar que Steuermann havia encontrado inúmeras e melhores soluções para a escrita dodecafônica. Citando especificamente a Suíte Para Piano de Steuermann, de 1952, afirmou que a considerava em muitos aspectos superior às Suítes para Piano de Schoenberg ${ }^{25}$.

A partir de 1951, Steuermann foi contratado para dar aulas regularmente na Juilliard School de Nova Iorque, atividade à qual se dedicou até 1964. Este fato, apesar de reafirmar e aumentar sua respeitabilidade como professor, significava também uma considerável carga extra de trabalho.

Suas apresentações como pianista, na Juilliard School, foram memoráveis: um Recital Schumann, que incluía a Kreisleriana op. 16 e as Davidsbündlertänze op.6; um Recital

\footnotetext{
${ }^{24}$ Gunther Schuller: compositor americano, nasceu em 1925. Começou seus estudos de música como trompista. Foi presidente do New England Conservatory de Boston, de 1966 a 1977. Muitas de suas obras utilizam-se do jazz, como por exemplo: Variants para quarteto de jazz e Conversations, para quarteto de jazz e quarteto de cordas. Entre suas obras inclui-se a opera The Visitation, o Concerto Festivo para quinteto de metais e orquestra e Museum Piece, para instrumentos renascentistas e orquestra. Faleceu em 2015.

${ }^{25}$ Informação verbal de Gunther Schuller aos autores deste artigo, em conversa realizada na Divisão de Música da Biblioteca do Congresso em Washington, D.C., Estados Unidos no dia 16 de dezembro de 2005. Nesse dia, Gunther Schuller foi homenageado - por ocasião da comemoração de seu $80^{\circ}$ aniversário - e recebeu o prêmio Living Legend Award.
} 
Beethoven, quando tocou uma de suas obras favoritas, as Variações Diabelli e um famoso recital Chopin, em 07 de março de 1962, que ficou na lembrança das pessoas que tiveram o privilégio de assistir, como uma leitura única das obras daquele compositor: uma total riqueza harmônica, repleta das mais formidáveis dissonâncias (CARTER, 1966, p.93).

Para muitas pessoas, esta foi uma das experiências musicais mais memoráveis dos últimos anos [...] como polonês, havia tentado encontrar em cada uma daquela peças aquilo que mais o interessava enquanto compositor e trazê-las à atenção dos ouvintes sem, logicamente, transgredir as intenções de Chopin (Ibid.)

Theodor Adorno, que foi aluno de Steuermann em 1921 e amigo durante toda a vida, comenta:

Sentia-se mais à vontade quando tocava de uma forma mais livre e relaxada na intimidade de um pequeno grupo de amigos, em situações que refletiam sua rejeição ao mercado musical e à cultura musical "oficial” (ADORNO, 1982, p. 315).

A oportunidade de voltar à Europa concretizou-se o através de vários convites recebidos para participar de cursos de verão em Salzburg, Darmstadt, e posteriormente em Israel. Mesmo tendo relutado muito em aceita-los, pois via com extrema cautela a situação da Europa no pósguerra, retornar também significou uma grande oportunidade de rever suas irmãs, Salka e Rosa, seus cunhados, sobrinhos e amigos. Salka, a exemplo de tantos outros europeus, fora obrigada a voltar à Europa, depois de ter sua vida investigada pelo FBI e ser denunciada como subversiva ${ }^{26}$.

Rachel, segunda filha de Edward e Clara, nasceu em 1958, o que aumentou a preocupação de Steuermann em relação a seus problemas financeiros. Empenhou-se cada vez mais em receber alunos, pois os convites para apresentações como pianista estavam ficando cada vez menos numerosos.

Em 1959 sua saúde começou a ficar debilitada e, após consultar vários especialistas, Steuermann foi diagnosticado com leucemia. Clara, com a evidente intenção de poupá-lo, não permitiu em nenhum momento que tivesse conhecimento de seu real estado de saúde.

A doença de Steuermann colocou-a frente a uma nova realidade: a perspectiva de ficar só, com duas crianças para criar, e sem absolutamente nenhuma ajuda. Matriculou-se na Columbia Library School em 1962 e obteve o título de Mestre em Biblioteconomia em 1964,

\footnotetext{
${ }^{26}$ Intelectuais e artistas que haviam imigrado para os Estados Unidos e colaborado de maneira definitiva para o desenvolvimento da cultura norte-americana viram-se se ameaçados pela obsessão da Guerra Fria entre Estados Unidos e União Soviética, o macarthismo. Estabelecido como uma verdadeira caça às bruxas, foi personificado pelo senador republicano Joseph McCarthy e perseguiu, violou direitos, condenou e extraditou supostos simpatizantes ou adeptos do comunismo.
} 
imaginando que seria mais fácil conseguir uma colocação com este título do que com seu título de Mestre em Artes.

Ainda no ano de 1962, Steuermann havia recebido na Academia Musical de Filadélfia o título de Doutor Honoris Causa em Música, como reconhecimento por seu trabalho como músico e como pedagogo.

Apesar de bastante debilitado, Steuermann ainda encontrou forças para continuar lecionando e compondo até praticamente seus últimos dias de vida. O Quarteto de Cordas "Diary" havia sido escrito em 1961. E duas de suas composições mais importantes, a Suíte para Orquestra de Cordas e a Cantata Kafka (Auf der Galerie) foram compostas em 1964.

Edward Steuermann morreu em Nova Iorque, em 11 de novembro de 1964, sem qualquer reconhecimento do mundo musical americano.

\section{Considerações Finais}

Quando Edward Steuermann se apresenta como o pianista da Segunda Escola de Viena, propagador de primeiras audições, encontramos um compositor moderno e autor de obra que figura junto aos catálogos de Webern, Berg e Eisler. Quem procura o compositor, pode ser surpreendido pelo professor de piano que encontrava menos tempo do que desejava para compor. Mas quando se constata que Steuermann foi professor de Alfred Brendel, Moura Limpany, Russel Sherman, Augustin Anievas, Menahem Pressler e tantos outros, é impossível não se dar conta do grande mestre do piano que não se contentava apenas em produzir virtuoses.

Mas, sem duvida, apenas um virtuose que escreveu obra tão importante e diversificada seria capaz de um caminho pedagógico firme e consciente, que privilegiava a música, e para quem a técnica era na verdade um meio, mas apenas um meio eficaz para se atingir um objetivo. $\mathrm{O}$ ato de escrever e compor proporcionou a Steuermann o pensar profundamente a música. As poucas gravações que deixou, como interprete e compositor, ainda continuam a ecoar o pensamento deste musico notável ${ }^{27}$.

\footnotetext{
${ }^{27}$ Edward Steuermann, Piano. Arnold Schoenberg Complete Piano Music. New York, Columbia Masterworks, ML 5216, 1957.Contemporary Records, S 8501, 1960. LP.

Edward Steuermann. Piano. Busoni's Toccata, Six Sonatinas 1\&6, Six Elegies.

Edward Steuermann, Piano. Hermann Scherchen,--Schoenberg Klavierkonzert op.42. Italy, Arkadia, CDGI 768.1. CD. 1993.

Edward Steuermann (Composer), Michael Gielen (Conductor). Five Pieces for Orhestra op. 10. Germany, Hänssler Classic - 93.060. CD. 2002.
} 
Poucos exemplos bem sucedidos podem ser encontrados na música destas últimas décadas. É verdade, eu repito, que estamos lidando aqui com uma expressão musical extremamente difícil que requer um estudo longo e paciente antes que se revelem seus segredos de força e beleza. Se alguém me pedisse para definir a maior característica da música de Edward Steuermann eu falaria, sem hesitar: sua originalidade. Isso não quer dizer que sua música não possua traços em comum com outras expressões musicais de nosso tempo. Nenhum artista verdadeiro poderia ou deveria desconsiderar as influências mais férteis do período no qual vive; pelo contrário, é talvez pela maneira como um artista absorve e transforma estas influências que reside uma parte de sua grandeza e é precisamente nesse processo de absorção e transformação que a originalidade de Steuermann se revela em sua plenitude (LEIBOWITZ, 1965-1966).

Para o compositor, as obras de Steuermann apontam para um desenvolvimento pessoal do estilo geral da escola de Schoenberg, mas de maneira absolutamente original (CARTER, 1966). O resultado de seu discurso musical conjuga grande agilidade, refinamento, sutileza de matizes e cores, e, acima de tudo, articulação, riqueza e lógica de encadeamento.

Para o professor, os testemunhos e realizações de seus alunos permanecem como mostras vivas de nível tão alto de pedagogia pianística do mestre das primeiras audições da Segunda Escola de Viena. E em todos os momentos em que cada uma dessas atividades de Edward Steuermann se mostra tão fascinante, é preciso lembrar e fazer reviver - através do estudo e da investigação de sua obra e de sua trajetória - seu ideal de luta em projetar a música para o futuro, o futuro presente para preservar o passado.

\section{Referências}

ADORNO, Theodor W. Gesamtausgabe, Vol.17, p.311-17. Suhrkamp Verlag, Frankfurt, 1982.

APPLEGATE, Celia; POTTER, Pamela. Germans as the "people of Music": Genealogy of an Identity. In: Music \& German National Identity. Edited by Celia Applegate and Pamela Potter. The University of Chicago Press, Chicago, 2002.

BERG, Alban. PRO MUNDO-PRO DOMO The Writings of Alban Berg. Edited by Bryan Simms. Oxford University Press, New York, 2016.

CALICO, Joy H. Schoenberg as a Teatcher. In: The Cambridge Companion to Schoenberg. Edited by Jennifer Shaw and Joseph Auner. Cambridge University Press, New York, 2010.

CARTER, Elliot. Current Chronical. In: The Musical Quarterly, 1966. Oxford University Press, Volume LII, Issue 1, pages 93-101, 1966.

LEIBOWITZ, René. An Evening in Memory of Edward Steuermann. In: Juilliard School of Music and The Edward Steuermann Memorial Society, Inc. New York, Program Season 1965-1966.

Edward Steuermann (Composer). Christopher O'Riley (Piano), Beverly Morgan (Soprano), Russell Sherman (Piano), Aki Takahashi (Piano), Paul Zukofsky (Violin). New York, Musical Observations, 1981. LP. 
McCOY, Marilyn. A Schoenberg Cronology. In: Schoenberg and His World, edited by Walter Frisch. Princeton University Press, New Jersey, 1999.

NEWLIN, Dika. Schoenberg Remembered. Pendragon Press, New York, 1980.

RIFKIND, Donna. The Sun and Her Stars. Salka Viertel and Hitler's Exiles in The Golden Age of Hollywood. Other Press, New York, 2020.

SCHULLER, Gunther. A Conversation with Steuermann. In: Perspectives of New Music, Princeton University Press, v. 3, n. 1, p. 22-35. New Jersey, 1964.

SCHULLER, Gunther. Gunther Schuller on Edward Steuermann and Schuller's Symphony for Brass. In: Interview with Jon Newson. Moldenhauer Archives, Divisão de Música, Biblioteca do Congresso, Washington D.C., Estados Unidos, 1995.

SHAWN, Allen. Arnold Schoenberg's Journey. Harvard University Press, Cambridge, 2003.

SMITH, Joan A. Schoenberg's Way In: Perspectives of New Music, Princeton University Press, Vol. $18, \mathrm{~N}^{\mathrm{o}} 1 / 2,1979-1980$.

STEUERMANN, Edward et al. Edward and Clara Steuermann Collection. Divisão de Música, Biblioteca do Congresso, Washington D.C., Estados Unidos, 1982.

STEUERMANN, Edward. The Not Quite Innocent Bystander. Writings of Edward Steuermann. Edited by Clara Steuermann, David Porter and Gunther Schuller. University of Nebraska Press, Lincoln, 1989.

STUCKENSCHMIDT, Hans Heinz. Arnold Schoenberg his life, world and work. John Calder Ltd., London, 1977.

VIERTEL, Salka. The Kindness of Strangers. Holt, Rinehart and Winston, New York, 1969.

ZANI, Heloisa. Correspondência: Clara e Edward Steuermann \& René Leibowitz. Tese de Doutorado. Universidade de São Paulo, São Paulo, 2002.

ZANI NETTO, Amilcar. Edward Steuermann: um esboço de figura. Tese de Livre-Docência. São Paulo: Universidade de São Paulo, 1991. 
